\title{
Quality International Education and Academic Prizes: SMA's Annual Conference in Perth has it all!
}

\author{
Liam Richard West, ${ }^{1}$ Julie Pham²,3
}

\begin{abstract}
The recent 2018 XXI Commonwealth Games held on the Gold Coast showcased remarkable sporting performances by athletes from around the world. Over 4000 athletes from 71 teams competed for 275 sets of medals. Australia made history for hosting the first major multi-sport event with equal numbers of events for males and females athletes. 1500 medical volunteers with backgrounds in elite and community based sport maned over 50 medical facilities across Games venues amassing 84,00 medical volunteer hours. Sports Medicine Australia (SMA) is extremely proud many volunteers were SMA members and we want to take this opportunity to thank the team behind the team! Much like the background of these volunteers and our members, we want to showcase a diverse range of papers within this SMA issue of the British Journal of Sports Medicine (BJSM).
\end{abstract}

\section{ADVANCES IN THE LOWER LIMB}

Despite advances in sports medicine, the battle to reduce the incidence of hamstring injuries is yet to be won. Joshua Ruddy and colleagues from the Australian Catholic University found an association between running exposure and subsequent hamstring strain injury (HSI) but unfortunately these absolute and relative variables don't predict HSI at the individual level (see page 919). Prakash's group from Melbourne have used these sports medicine advances to develop a novel MRI grading system that examines the integrity of connective tissue to help us more reliably estimate and guide the return to play in calf muscle tears (see page 929). Staying with MRI, Andreas Serner and colleagues have created a fantastic infographic based on their research that tested whether standardised clinical examination of athletes with acute groin injuries could predict the

'Olympic Park Sports Medicine Centre, Melbourne, VIC, Australia

${ }^{2}$ Cottesloe Podiatry Centre, Cottesloe, Western

Australia, Australia

${ }^{3}$ Allsports \& Family Podiatry and Physiotherapy, West Leederville, Western Australia, Australia

Correspondence to Dr Liam Richard West, Olympic Park Sports Medicine Centre, Melbourne, VIC, Australia; liamwestsem@hotmail.co.uk

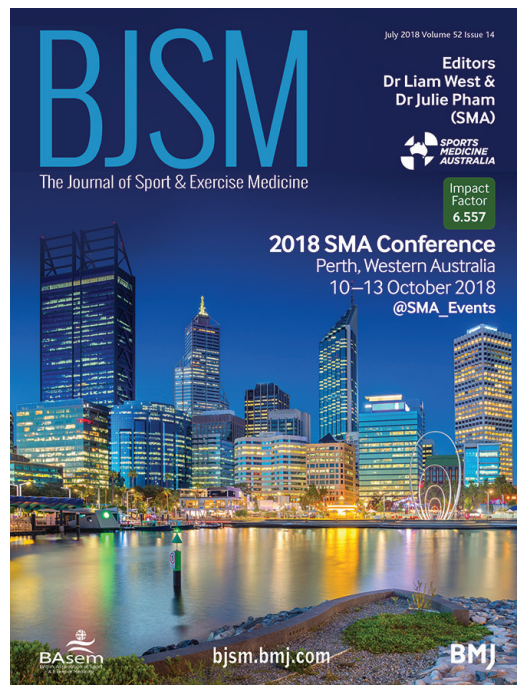

to drugs of abuse such as opioids, from the standpoint of brain neurochemistry as well as behaviour (see page 910).

\section{PHYSICAL ACTIVITY POLYPILL}

We are all aware at each clinic visit, we should aim to prescribe the physical activity polypill to patients. Mitch Duncan's group share how and why the 10000 Steps Australia programme has been such a success at improving community wide physical activity levels (see page 885 ). In his review, Urho Kujala explains that the undisputed health benefits of physical activity are yet to translate into any proven casual relationship for longevity if this activity is only started in adulthood (see page 914).

\section{NFL CONCUSSION GUIDELINES}

SMA has a leading role in engaging the community to participate in sport and physical activity safely. Fittingly, the final paper from this issue we want to highlight is an updated protocol for concussion diagnosis and management that was developed by the NFL Head, Neck and Spine Committee during the 2017/18 season (see page 894 ).

presence and location of MRI findings (see page 892 ). Imaging has also been utilised by Jackie Whittaker's group whom showed that MRI-detected osteoarthritic structural changes 3-10 years following youth sport-related knee injury may not dictate clinical symptomatology, strength or function but may influence quality of life (see page 934).

Staying in the lower limb, we want to highlight the editorial from La Trobe's tendon expert Jill Cook on the ten treatments we should avoid in lower limb tendon pain (see page 882). Another treatment to avoid is arthroscopy in the degenerative knee according to Kay Crossley and her La Trobe University group. They discuss what other credible treatment options we should be considering in their editorial in this issue (see page 884). On to things we should do.

\section{FOOD FOR THOUGHT}

This SMA issue of the BJSM contains some thought provoking reviews. Sydney's Maryanne Demasi explores the history behind statins and questions whether there is the evidence to back their widespread use in heart disease (see page 905). There is a growing perception that sugar intake is a larger public health risk than cholesterol levels. James DiNicolantonio states that sugar can be considered an addictive substance similar

\section{INVITATION TO THE 2018 SMA CONFERENCE}

Fantastic scenary. Packed scientific programme. Vibrant social calender. The 2018 SMA Conference has it all! On 10th13th November at the Perth Convention and Exhibition Centre we will be showcasing the most influential researchers and practitioners across the various disciplines within Sport \& Exercise Medicine (figure 1). We are also excited to announce that this year there is over $\$ 23000$ worth of funds to be awarded to papers of excellence in clinical sports medicine, sports and exercise science, physical activity and health promotion, and sports injury prevention. Head to the website - smaconference.org.au - to find out more. We look forward to seeing you there!

Competing interests None declared.

Patient consent Not required.

Provenance and peer review Commissioned; internally peer reviewed.

(C) Author(s) (or their employer(s)) 2018. No commercial re-use. See rights and permissions. Published by BMJ.

$$
\text { D Check for updates }
$$

To cite West LR, Pham J. Br J Sports Med 2018;52:881.

Br J Sports Med 2018;52:881.

doi:10.1136/bjsports-2018-099615 